\title{
College campuses and COVID-19 mitigation: clinical and economic value
}

\author{
Elena Losina, $\mathrm{PhD}$ 1,2,3,4 \\ Valia Leifer, $\mathrm{AB}{ }^{1,2}$ \\ Lucia Millham, $\mathrm{AB}^{3,5}$ \\ Christopher Panella, BS ${ }^{5}$ \\ Emily P. Hyle, MD, MSc ${ }^{3,5,6}$ \\ Amir M. Mohareb, MD 5,6 \\ Anne M. Neilan, MD, MPH ${ }^{5,6,8}$ \\ Andrea L. Ciaranello, MD, MPH ${ }^{3,5,6}$ \\ Pooyan Kazemian*, PhD $^{9}$ \\ Kenneth A. Freedberg*, MD, MSc ${ }^{3,5,6,7,10}$
}

* Drs. Kazemian and Freedberg contributed equally to this work

Affiliations:

1. Policy and Innovation eValuation in Orthopedic Treatments (PIVOT) Center, Department of Orthopedic Surgery, Brigham and Women's Hospital, Boston, MA

2. Orthopedic and Arthritis Center for Outcomes Research (OrACORe), Department of Orthopedic Surgery, Brigham and Women's Hospital, Boston, MA

3. Harvard Medical School, Boston, MA

4. Department of Biostatistics, Boston University School of Public Health, Boston, MA 
5. Medical Practice Evaluation Center, Massachusetts General Hospital, Boston, MA

6. Division of Infectious Diseases, Department of Medicine, Massachusetts General Hospital, Boston, MA

7. Division of General Internal Medicine, Department of Medicine, MGH, Boston, MA

8. Division of General Academic Pediatrics, Department of Pediatrics, Massachusetts General Hospital, Boston, MA

9. Department of Operations, Weatherhead School of Management, Case Western Reserve University, Cleveland, $\mathrm{OH}$

10. Department of Health Policy and Management, Harvard T. H. Chan School of Public Health, Boston, MA

Corresponding author:

Elena Losina, $\mathrm{PhD}$

Orthopedic and Arthritis Center for Outcomes Research

Brigham and Women's Hospital

60 Fenwood Rd, 5016

Boston, MA, 02115

Word Count:

Abstract: 200 words

Text: 2,942 words

Running title: COVID-19 mitigation on college campuses 


\begin{abstract}
Background: Decisions around US college and university operations will affect millions of students and faculty amidst the COVID-19 pandemic. We examined the clinical and economic value of different COVID-19 mitigation strategies on college campuses.
\end{abstract}

Methods: We used the Clinical and Economic Analysis of COVID-19 interventions (CEACOV) model, a dynamic microsimulation that tracks infections accrued by students and faculty, accounting for community transmissions. Outcomes include infections, \$/infection-prevented, and \$/quality-adjusted-life-year (\$/QALY). Strategies included extensive social distancing (ESD), masks, and routine laboratory tests (RLT). We report results per 5,000 students (1,000 faculty) over one semester (105 days).

Results: Mitigation strategies reduced COVID-19 cases among students (faculty) from 3,746 (164) with no mitigation to 493 (28) with ESD and masks, and further to 151 (25) adding $R L T q 3$ among asymptomatic students and faculty. ESD with masks cost \$168/infection-prevented (\$49,200/QALY) compared to masks alone. Adding RLTq3 (\$10/test) cost \$8,300/infectionprevented $(\$ 2,804,600 / \mathrm{QALY})$. If tests cost $\$ 1, R L T q 3$ led to a favorable cost of $\$ 275 /$ infectionprevented (\$52,200/QALY). No strategies without masks were cost-effective.

Conclusion: Extensive social distancing with mandatory mask-wearing could prevent $87 \%$ of COVID-19 cases on college campuses and be very cost-effective. Routine laboratory testing would prevent $96 \%$ of infections and require low cost tests to be economically attractive.

Key words: COVID-19, college campuses, mitigation 


\section{Introduction}

Over 2,000 colleges and universities in the United States with over 20 million students are trying to determine how to minimize the impact of the COVID-19 on their students, faculty, the surrounding communities and health care systems [1]. Higher education is a $\$ 671$ billion/year industry employing over 3.6 million people [1]. High contact rates and close living conditions among students increase the risk of infection, and more than one-third of the 1.5 million faculty are over age 55, which raises their risk of morbidity and mortality from COVID-19 [2, 3]. All of this has major implications for its impact on laboratory testing and hospital capacity in the communities, towns and cities where colleges are located.

In concert with clinical leaders and local health systems and governments, colleges must balance multiple factors in their decision-making. While teaching online only would reduce campus-based transmissions, doing so might reduce quality of education, lower graduation rates, increase long-term mental health problems among students and decrease college revenue [4]. Frequent laboratory testing would require coordination between laboratories and colleges and a mechanism of acting upon tests results by isolating those with positive tests. Given these tradeoffs, multiple strategies are being considered and implemented to mitigate transmission among students and faculty, while allowing colleges to maintain some in-person teaching.

Programs under consideration include combinations of non-pharmacologic interventions (NPIs), such as reducing class sizes through hybrid (in-person and online) education methods, timing access to libraries and dining halls, cancelling large events, suspending athletic programs, and implementing mandatory mask-wearing policies [5]. Colleges are considering these NPIs in concert with different methods of symptom surveillance and laboratory testing approaches [6], as 
medRxiv preprint doi: https://doi.org/10.1101/2020.09.03.20187062; this version posted September 5, 2020. The copyright holder for this preprint (which was not certified by peer review) is the author/funder, who has granted medRxiv a license to display the preprint in perpetuity.

All rights reserved. No reuse allowed without permission.

well as different isolation strategies for symptomatic students or those with confirmed COVID-

19, such as using designated dormitories or renting nearby hotels [7].

Colleges are developing these strategies at the same time as evidence about the effectiveness of social distancing and masks, the accuracy and cost of laboratory tests, and the feasibility of designated isolation is rapidly evolving $[8,9]$. We examined the impact of different COVID-19 mitigation strategies on clinical and economic outcomes in college settings. 


\section{Methods}

Analytic overview

We used the validated Clinical and Economic Analysis of COVID-19 interventions (CEACOV) model, a dynamic microsimulation of the natural history of COVID-19 built on susceptible-infected-recovered (SIR) principles [10]. We considered contacts among students, faculty, and the surrounding community $[11,12]$ and assessed clinical outcomes among students and faculty, including prevalent and incident infections, isolation unit use, laboratory tests, and hospital and intensive care unit (ICU) utilization. The CEACOV models infections to students and faculty occurring from students, faculty, or community. Transmission rates within and across groups are based on estimated contact-hours for each, and the SARS-CoV-2 infectivity rate per contact-hour [13]. Costs included NPIs, testing, and hospital-related. Using quality of life (QoL) decrements for similar illnesses, we modeled QoL decrements for COVID-19 [14, 15]. We accounted for a daily proportion of individuals with influenza-like illness (ILI) unrelated to SARS-CoV-2 infections [16-18]. Outcomes included the projected clinical impact, cost, budget impact, and cost-effectiveness of alternative mitigation strategies over one semester (105 days). We calculated incremental cost-effectiveness ratios (ICERs), the difference in costs divided by the difference in quality-adjusted life-years (QALYs) saved for different strategies [19], and determined cost/infection-prevented. We described results for 5,000 students and 1,000 faculty within a surrounding community of 100,000 people. 


\section{Strategies}

We considered two 'background' strategies for comparison where: 1) campus remains closed (CampusClosed) with only online education, and 2) campus operates as it did before COVID-19, without any mitigation interventions (NoIntervention).

We examined 24 mitigation strategies based on 4 approaches: 1) social distancing (SocDist); 2) mask-wearing policies (Masks), 3) isolation, and 4) laboratory testing (LT). LT ranged from no testing of asymptomatic students, to routine laboratory testing of asymptomatic students $(R L T)$ at 14,7 , or 3 day intervals. We modeled two SocDist strategies: minimal social distancing (MinSocDist), including cancelling sports and university-sponsored concerts, and extensive social distancing (ExtSocDist), where $100 \%$ of large classes and $50 \%$ of smaller classes were delivered online. We also considered a strategy that combined ExtSocDist and Masks (ExtSocDist+Masks). Social distancing reduced contact-hours with infected persons and masks reduced infectivity of infected individuals. All 24 strategies utilized symptom screening. Positive results from symptom screens and laboratory tests led to isolation, which further reduced contacts between infected and susceptible individuals.

We examined two isolation-strategies for students with positive symptom screens or laboratory tests: 1) residence-based isolation (ResIsol), and 2) designated spaces (DesigIsol). Each reduced contact-hours between infected and susceptible individuals. DesigIsol was more restrictive than ResIsol. 


\section{CEACOV model structure}

\section{Disease states and progression}

CEACOV is a dynamic microsimulation of SARS-CoV-2 [11, 12]. Susceptible individuals have a daily probability of getting infected. Infected individuals experience a daily probability of advancing in COVID-19 disease severity, which increases with age, and includes risk of hospitalization, ICU admission, and death. CEACOV includes 6 COVID-19 disease states: pre-infectious latency, asymptomatic, mild/moderate, severe, critical, and recuperation. In this analysis, we assume that all individuals recovered from COVID-19 are immune from reinfection for the remainder of the semester.

\section{$\underline{\text { Transmissions }}$}

CEACOV captures the heterogeneity of viral transmission among students, faculty, and community. The overall force of infection depicting transmission risk from infected to susceptible individuals is distributed across transmission groups, weighted by group size and contact-hours within and across the 3 groups. The transmission rate is based on contacthours/day and a derived infectivity rate/contact-hour. Social distancing reduces contact hours within and between groups. Masks reduce the infectivity rate [8].

$\underline{\text { Costs and quality of life }}$

We included the cost of NPIs, isolation units, testing, and hospitalization. NPI costs included those of: 1) implementation/maintenance of online learning platforms, 2) masks, and 3) 
cleaning/disinfecting measures. Strategy-specific costs depend on the NPIs in place. Collegesponsored DesigIsol costs include the cost/day of designated isolation units. While mild/moderate COVID-19 symptoms are assumed to resolve with over-the-counter or no medications, severe or critical disease results in hospitalization or ICU costs.

For mild/moderate COVID-19, we estimated QoL losses based on utility decrements from influenza [15]. For all students, regardless of symptom state, we modeled decreased QoL for time students spent in isolation to account for the effects of isolation on mental health [20]. We derived QoL decrements for hospitalized individuals using data for complicated pneumonia [14]. The impact of mortality on QALYs lost is described in Supplementary Materials. We did not model any long-term complications from COVID-19.

\section{Input parameters}

\section{Cohort characteristics}

We derived demographic characteristics of students, faculty, and community using data from colleges and their surrounding typical college towns [21, 22]. (See Supplementary Materials).

\section{$\underline{\text { Contact-hours }}$}

We derived contact-hours, defined as a single hour spent with a single person, within the same and across transmission groups (Table 2). We estimated contact-hours prior to COVID-19 epidemic as a basis for reduction in contact-hours in social distancing strategies. 
Students: Contact-hours for students include time spent with roommates, in group study, office hours with faculty, in lectures, and in recreational, sporting, work-for-pay, shopping, and social activities. We estimated that students spend 149 contact-hours/day with each other, 1.5 contact-hours/day with faculty, and 3.9 hours/day with community members.

Faculty: We estimated that faculty spend, on average, 10 contact-hours/day with other faculty, 37 contact-hours/day with students (25 of which are teaching), and 33 contact-hours/day with community (including family).

Community: We estimated that community members spend 81 contact-hours/day interacting with others in the community, including time with family, work, shopping, and socializing.

\section{$\underline{\text { SARS-CoV-2 infectivity }}$}

We derived the infectivity/contact-hour rate from a study of household infections in Wuhan, China (0.002/contact-hour, Supplementary Materials) [13]. Per CDC guidelines, we assumed an infectivity duration of 10 days [23].

\section{Efficacy of NPIs}

Social distancing: MinSocDist decreased student-student contact-hours by $26 \%$ and reduced the overall daily transmission rate from $0.238(\mathrm{Rt}=2.38)$ to $0.167(\mathrm{Rt}=1.67$, Table 1$)$. ExtSocDist decreased student-student contact hours by 39\%, student-faculty contact-hours by 
$50 \%$, and faculty-student contact-hours by $60 \%$, and reduced the overall daily transmission rate to $0.141(\mathrm{Rt}=1.41)$.

Masks: The reported efficacy of masks in reducing infectivity ranges between $44 \%$ and $82 \%$ [9]. Recognizing that students may use different types of masks and not wear them at all times, we used a base-case infectivity reduction for masks of $50 \%$ and adherence of $50 \%$, and varied these parameters in sensitivity analyses [8]. The overall daily transmission rates for the Masks and ExtSocDist+Masks strategies were $0.128(\mathrm{Rt}=1.28)$ and $0.105(\mathrm{Rt}=1.05)$, respectively.

To capture the potential 'fatigue' that students, faculty, and community might experience in terms of complying with NPIs we used 'transmission rate multipliers' to increase transmission rates by $25 \%$ for the second month of the semester, and $50 \%$ for the last two months.

\section{$\underline{\text { Laboratory test characteristics }}$}

We assumed 50\% accuracy in terms of students' ability to self-screen [24], and 90\% for faculty. We also assumed those with positive symptom screens have a $60 \%$ chance of adhering to ResIsol and $100 \%$ adherence to DesigIsol. We stratified the sensitivity of laboratory testing by days post-infection using published PCR test data (Table 1) [25]. We assumed 100\% laboratory test specificity and modeled a 1-day delay to receiving test results.

\section{$\underline{\text { COVID-19 clinical characteristics }}$}

Using published literature, we derived the probability of progressing to more severe COVID-19 disease stages (Table 1A, Supplementary Materials). 


\section{$\underline{\text { Costs }}$}

We considered costs from a modified societal perspective, including mitigation costs associated with prevention of COVID-19 and direct medical costs related to COVID-19 treatment. Indirect costs such as lost productivity due to isolation were captured in utilities measures. For all 24 NPI-based strategies we accounted for the cost of additional cleaning, estimating these costs would increase by $\sim 50 \%$, or $\$ 31.50 /$ student/semester, relative to before the pandemic [26]. For the Masks and ExtSocDist+Masks strategies we included cost of masks, with one $\$ 2$ cloth mask/week, and one $\$ 0.10$ disposable mask/day for each student and faculty member $(\$ 212,500 /$ semester in total). Total NPI costs per semester were $\$ 151,500$ for MinSocDist, $\$ 407,500$ for ExtSocDist, and \$620,000 for ExtSocDist+Masks. In base case analyses, we assumed colleges would negotiate a SARs-2-CoV test cost of $\$ 10(\sim 25 \%$ of the lowest currently published pricing) [27]. We use Health Care Utilization Project (HCUP) data to derive per-day costs for hospital and ICU care $(\$ 1,640$ and $\$ 2,680$, Table 1$)$. We estimated the cost of college-sponsored DesigIsol at \$30/day, between the maintenance cost/student/day (\$5) [26] and the daily cost of room and board (\$55) [28].

$\underline{\text { Sensitivity analyses }}$

In sensitivity analyses we varied the efficacy of masks (50\%-67\% infectivity reduction), students' adherence to wearing masks (50\%-80\%), and the sensitivity of laboratory tests (5090\%). We varied the costs of: 1) laboratory testing (\$1-\$51), 2) a daily DesigIsol unit (\$5-\$55), and 3) online educational software $(\$ 100,000-\$ 500,000$ per semester for 5,000 students and 1,000 faculty) [29]. We also conducted a 'threshold' analysis to determine what percentage of students would need to defer for a semester (not pay tuition) to make the CampusClosed strategy 
medRxiv preprint doi: https://doi.org/10.1101/2020.09.03.20187062; this version posted September 5, 2020. The copyright holder for this preprint (which was not certified by peer review) is the author/funder, who has granted medRxiv a license to display the preprint in perpetuity.

All rights reserved. No reuse allowed without permission.

clinically and economically worse than other strategies. We also determined the laboratory test cost that produced an ICER $<\$ 150,000 /$ QALY [30]. 


\section{Results}

Clinical outcomes: cumulative infections (Table 2, Figure 1)

We estimate that the NoIntervention strategy will lead to infections among $75 \%(17 \%)$ of students (faculty), or 3,699 incident (155) and 47 (10) prevalent infections per 5,000 students and 1,000 faculty. The CampusClosed strategy will lead to 1,401 (26) student (faculty) infections, with most student infections coming from other students living off campus. The MinSocDist strategy with self-screen or one-time laboratory testing at the semester start will reduce student infections by $16 \%$ relative to NoIntervention. Adding laboratory testing (every 3 days (RLTq3)) of asymptomatic students to MinSocDist will lead to 713 (54) infections in students (faculty). ExtSocDist will lead to 1,927-2,188 (52-73) student (faculty) infections without routine testing and 274 (35) student (faculty) infections with RLTq3. Masks is a more effective strategy alone than either MinSocDist or ExtSocDist, with 1,456 (48)-1,519 (51) student (facuty) infections without $R L T$ and 215 (26) infections with $R L T q 3$ testing of asymptomatic students. ExtSocDist+Masks leads to 493 (28)-606 (28) student (faculty) infections without testing and to 151 (25) with RLTq3. Relative to ResIsol, without RLT, DesigIsol did not meaningfully reduce infections.

\section{Clinical outcomes: hospital use}

We estimate that NoIntervention strategy would lead to 217 (8) hospital (ICU) days among students and 40 (12) days among faculty. ExtSocDist+Masks would reduce the number of hospital days by $87 \%$ (95\%) among students (faculty) to 29 and 2 hospital-days, respectively. Adding $R L T q 3$ would further reduce the number of hospital days to 7 (6) for students (faculty). 
medRxiv preprint doi: https://doi.org/10.1101/2020.09.03.20187062; this version posted September 5, 2020. The copyright holder for this preprint (which was not certified by peer review) is the author/funder, who has granted medRxiv a license to display the preprint in perpetuity.

All rights reserved. No reuse allowed without permission.

Economic Evaluation (Table 3, Figure 3)

Budgetary impact

CampusClosed cost $\$ 1,099,181$, if 100 students (2\%) took a 'gap semester.' Without RLT, MinSocDist cost \$414,749-\$558,213, ExtSocDist cost \$551,693-\$663,983, Masks cost \$448,254-\$600,876, ExtSocDist+Masks cost \$664,015-\$757,625. Adding RLTq3 to ExtSocDist+Masks or MinSocDist led to a total cost of \$2,103,264.

$\underline{\text { Cost-effectiveness }}$

Different strategies led to substantially different costs/infection-prevented and costs/QALY (Table 3, Figure 3). MinSocDist was never economically efficient. Alone, Masks cost \$76/infection-prevented (\$17,300/QALY). We estimated the incremental value of ExtSocDist+Masks to be \$168/infection-prevented (ICER: \$49,200/QALY). Adding RLTq14 to ExtSocDist+Masks led to a cost of \$2,008/infection-prevented (ICER: \$811,400/QALY). Adding more frequent testing prevented more infections, but cost much more, at \$4,596/infectionprevented for $R L T q 7$ and $\$ 8,322 /$ infection-prevented for $R L T q 3$, both with ICERs $>\$ 1$ M/QALY.

Sensitivity Analyses

Without $R L T$, the value of ExtSocDist depended on its cost. If ExtSocDist's implementation costs doubled, from $\$ 250,000$ to $\$ 500,000$, ExtSocDist + ResIsol cost \$250/infection-prevented (\$53,000/QALY). The most influential factors affecting the value of $R L T$ were test costs and frequency. If test costs were lowered to $\$ 1 /$ test, then adding $R L T q 3$ to Masks led to a favorable cost of $\$ 275 /$ infection-prevented (\$52,200/QALY); with a $\$ 3 /$ test, 
medRxiv preprint doi: https://doi.org/10.1101/2020.09.03.20187062; this version posted September 5, 2020. The copyright holder for this preprint (which was not certified by peer review) is the author/funder, who has granted medRxiv a license to display the preprint in perpetuity.

All rights reserved. No reuse allowed without permission.

adding $R L T q 7$ cost $\$ 358 /$ infection-prevented $(\$ 120,500 / \mathrm{QALY})$. At a test cost greater than $\$ 5$, even the least frequent strategy considered, $R L T q 14$, produced ICERs $>\$ 300,000 / \mathrm{QALY}$. 


\section{Discussion}

We conducted a model-based evaluation of the impact of COVID-19 mitigation strategies on college campuses, taking into consideration heterogeneous transmission across students and faculty, and accounting for transmission from the surrounding community. We examined the value of social distancing and mask-wearing policies, and the use of routine laboratory testing of asymptomatic students and faculty. We had 3 major findings. First, even if campuses remain closed, there will likely be many infections among faculty from the surrounding community, and among students from students returning to live off campus in and around the college town.

Second, while minimal social distancing, such as cancelling large events, would reduce some infections, and extensive social distancing with a hybrid educational system would lead to even fewer infections, a mandatory mask-wearing policy alone would reduce infections the most. Combining a mask-wearing policy with extensive social distancing would prevent $87 \%$ of infections among students and faculty, and would cost \$168/infection-prevented (\$49,200/QALY saved). Third, while adding a strategy of RLTq14 to a combined social distancing and maskwearing policy would reduce infections, it would do so at a much higher cost/infectionprevented, even at \$10/test (25\% of currently available lowest pricing) compared to the value of ExtSocDist+Masks. Reducing test costs to $\$ 1 /$ test, would lead strategies with even every 3 day testing to prevent infections with much better value.

We also found that while most infections among students were from other students, most infections in faculty were not from students, since faculty live off campus and spend a substantial amount of time in their community-based social networks. 
While adding RLT to ExtSocDist+Masks further reduced infections, this strategy is costly and less economically efficient than ExtSocDist+Masks without $R L T$ at a test cost of $\$ 10$. Even if colleges are able to support the financial and operational burden of testing, other factors, such as laboratory capacity and the availability of testing supplies, may impact the feasibility of this strategy in states such as Massachusetts, where $>100$ colleges have a combined student population >500,000 [1]. In Massachusetts, RLTq14 would require 36,000 tests daily for students alone, which could divert testing resources away from symptomatic, non-student populations, or those who have been in close contact with confirmed COVID-19-infected individuals. With these trade-offs in mind, it is critical to implement and maintain mitigation programs that do not depend completely on testing capacity, such as extensive social distancing and mask-wearing policies.

Two recent studies have examined COVID-19 mitigation strategies for US colleges. Paltiel et al. examined routine surveillance screening under several epidemic scenarios defined by Rt 1.5-3.5 [31]. Consistent with our analysis, their study suggests more frequent testing prevented more infections. Differences in the apparent value of routine laboratory testing between our analyses likely result from our explicit modeling of social distancing and maskwearing policies, which produced Rt values much lower than the ranges considered by Paltiel et al. A report from Cornell also found that routinely testing asymptomatic students would prevent the most infections. While this report suggested pooling specimens to reduce testing costs, no explicit economic analysis was presented [32]. Similar to our analysis, they report that keeping campuses closed may yield more infections than bringing students back to campus with comprehensive NPIs. 
These results should be viewed in the context of several limitations. First, while we tried to capture the major COVID-19 mitigation strategies that colleges and universities are considering, we examined only a limited number of strategies. We also did not capture all potential externalities that these institutions might face, such as lost revenue from cancelled sports and the impact of social distancing on students' quality of life, and we did not examine the impact of contact tracing on transmission. Finally, there continues to be uncertainty about many aspects of COVID-19 testing and immune response. We used the best currently available data and limited our analysis to the duration of one semester.

In conclusion, implementing extensive social distancing and mandatory mask-wearing policies would enable higher education institutions to have the biggest impact in reducing COVID-19 infections among students and faculty. Routine laboratory testing would further reduce infections but would require less costly tests coupled with markedly increased capacity to be feasible for many colleges. 


\section{Figure legends}

Figure 1. Infections and costs by COVID-19 mitigation strategy

Panels A and B represent the number and source of infections in students (Panel A) and faculty (Panel B) for each strategy; panel C depicts total costs. On the left are the NoIntervention and CampusClosed strategies. The 4 broad NPI-strategies (minimal social distancing, extensive social distancing, mask-wearing policy, and combined extensive social distancing and mask policy) are further stratified by the use and frequency of laboratory testing (LT), from no LT, where those who report symptoms associated with COVID-19 are asked to isolate in their residence for 10 days, to one LT for those who report symptoms to confirm placement in isolation, to routine LTs (RLTs) for all students and faculty at the start of semester, to routine LT among asymptomatic students and faculty at 3, 7, or 14-days intervals. Infections decrease as strategies increase in intensity, from minimal social distancing to the combined extensive social distancing and mask-wearing policy strategy. In each case, adding LT further decreases infections. Among students, the vast majority of infections are from other students (Panel A). Among faculty, depending on the strategy, most infections are from the community and other faculty (Panel B). In strategies without routine lab testing, hospital and ICU costs represent over $50 \%$ of costs (Panel C). In strategies with routine LT, testing is over $50 \%$ of the total cost. See Methods section for strategy name abbreviations.

Figure 2. Efficiency Frontier (\$/infection prevented)

The efficiency frontier represents the relationship between infections prevented (vertical axis) and total costs (horizontal axis). NoIntervention is shown in the open red circle on the lower left. 
Without routine laboratory testing or testing at the semester start, regardless of isolation approach, there is clustering (depicted by ovals) of strategies involving minimal social distancing (triangles), extensive social distancing (circles), mask policy (diamonds), and combined extensive social distancing with mask policy (squares). Grey ovals represent strategies where masks are not incorporated, while beige ovals represent clustering of strategies where masks are incorporated; showing more infections prevented when masks are incorporated. Symbols on the solid black line represent economically efficient strategies. The slope of the solid line represents the incremental cost/infection-prevented for each strategy, compared to the next less costly efficient strategy. Testing at 14,7 , or 3 day-intervals prevents additional infections, but at a substantially increased cost/infection-prevented. 
medRxiv preprint doi: https://doi.org/10.1101/2020.09.03.20187062; this version posted September 5, 2020. The copyright holder for this preprint

(which was not certified by peer review) is the author/funder, who has granted medRxiv a license to display the preprint in perpetuity.

All rights reserved. No reuse allowed without permission.

\section{Notes}

No authors have any potential conflicts of interest.

The work was funded by NIAID R37AI058736-16S1.

For all correspondence and requests for reprints, please contact:

Elena Losina, $\mathrm{PhD}$

E-mail: elosina@partners.org

Address: 60 Fenwood Rd, 5016, Boston, MA, 02115 


\section{Literature cited}

1. UnivStats, Total number of Employees at U.S. Colleges by occupation. 2019: https://www.univstats.com/. Acessed 9/2/2020

2. McChesney, J., The Aging of Tenure-Track Faculty in Higher Education: Implications for Succession and Diversity (Research Report). 2020, College and University Professional Association for Human Resources.

3. Clark, A., et al., Global, regional, and national estimates of the population at increased risk of severe COVID-19 due to underlying health conditions in 2020: a modelling study. The Lancet Global Health, 2020. 8(8): p. e1003-e1017.

4. Depietro, A., Here's A Look At The Impact Of Coronavirus (COVID-19) On Colleges And Universities In The U.S. 2020: Forbes. https://www.forbes.com/sites/andrewdepietro/2020/04/30/impact-coronavirus-covid-19colleges-universities/\#19aa220f61a6. Acessed 9/2/2020

5. Hadden, J., What the top 25 colleges and universities in the U.S. have said about their plans to reopen in fall 2020, from postponing the semester to offering more remote coursework. Business Insider. 2020. https://www.businessinsider.com/how-major-uscolleges-plan-reopen-for-fall-2020-semester-2020-5. Accessed 9/2/2020.

6. Radsken, J., Faculty of Arts and Sciences will bring up to $40 \%$ of undergraduates to campus this fall. Harvard Gazette. 2020. https://news.harvard.edu/gazette/story/2020/07/

7. Logan, T., Dorm rooms at the Westin? Hotels and universities are teaming up to offer socially distanced student housing, in Boston Globe. 2020. https://www.bostonglobe.com/2020/07/26/business/dorm-rooms-westin-hotels-universitiesare-teaming-up-offer-socially-distanced-student-housing/ 
8. Stutt, R.O.J.H., et al., A modelling framework to assess the likely effectiveness of facemasks in combination with \&\#x2018;lock-down\&\#x2019; in managing the COVID19 pandemic. Proceedings of the Royal Society A: Mathematical, Physical and Engineering Sciences, 2020. 476(2238): p. 20200376.

9. Chu, D.K., et al., Physical distancing, face masks, and eye protection to prevent personto-person transmission of SARS-CoV-2 and COVID-19: a systematic review and metaanalysis. The Lancet, 2020. 395(10242): p. 1973-1987.

10. Hethcote, H.W., The Mathematics of Infectious Diseases. SIAM Review, 2000. 42(4): p. 599-653.

11. Reddy, K.P., et al., Cost-effectiveness of public health strategies for COVID-19 epidemic control in South Africa. medRxiv, 2020: p. 2020.06.29.20140111.

12. Neilan, A.M., et al., Clinical Impact, Costs, and Cost-Effectiveness of Expanded SARSCoV-2 Testing in Massachusetts. MedRxiv, doi: https://doi.org/10.1101/2020.07.23.20160820

13. Li, W., et al., Characteristics of Household Transmission of COVID-19. Clinical Infectious Diseases, 2020. ciaa450, https://doi.org/10.1093/cid/ciaa450

14. Andrade, L.F., et al., Health related quality of life in patients with community-acquired pneumococcal pneumonia in France. Health and quality of life outcomes, 2018. 16(1): p. 28-28.

15. Yang, J., et al., The impact of influenza on the health related quality of life in China: an EQ-5D survey. BMC infectious diseases, 2017. 17(1): p. 686-686. 
medRxiv preprint doi: https://doi.org/10.1101/2020.09.03.20187062; this version posted September 5, 2020. The copyright holder for this preprint (which was not certified by peer review) is the author/funder, who has granted medRxiv a license to display the preprint in perpetuity.

All rights reserved. No reuse allowed without permission.

16. Wang, D., et al., Clinical Characteristics of 138 Hospitalized Patients With 2019 Novel Coronavirus-Infected Pneumonia in Wuhan, China. JAMA, 2020. 323(11): p. 10611069.

17. Center for Diseases Control and Prevention. Percentage of visits of ILI by age group reported by a subset of ILINet providers. 2020. https://www.cdc.gov/coronavirus/2019ncov/covid-data/covidview/08282020/percent-ili-visits-age.html. Accessed 9/2/2020.

18. Why a study showing that covid-19 is everywhere is good news. Economist, 2020. https://www.economist.com/graphic-detail/2020/04/11/why-a-study-showing-that-covid-19-iseverywhere-is-good-news. Accessed 9/2/2020.

19. Carias, C., et al., Recommendations of the Second Panel on Cost Effectiveness in Health and Medicine: A Reference, Not a Rule Book. American Journal of Preventive Medicine, 2018. 54(4): p. 600-602.

20. Kolovos, S., et al., Utility scores for different health states related to depression: individual participant data analysis. Quality of life research : an international journal of quality of life aspects of treatment, care and rehabilitation, 2017. 26(7): p. 1649-1658.

21. Most Students Living in University Housing. College Compass [cited 2020 8/4/2020]; Available from: usnews.com/best-colleges/rankings/most-on-campus. Accessed 9/2/2020.

22. College Navigator. National Center for Education Statistics.

23. Center for Diseases Control and Prevention: Duration of Isolation and Precautions for Adults with COVID-19. 2020.

24. Jeong, H., et al., Discordance between self-report and clinical diagnosis of Internet gaming disorder in adolescents. Scientific Reports, 2018. 8(1): p. 10084. 
25. Variation in False-Negative Rate of Reverse Transcriptase Polymerase Chain ReactionBased SARS-CoV-2 Tests by Time Since Exposure. Annals of Internal Medicine. 0(0): p. null.

26. Agron, J., 38th Annual Maintenance \& Operations Cost Study for Colleges. 2009: American School \& University.

27. Medicare Administrative Contractor. COVID-19 test pricing. 2020.

28. University, T. Cost and Aid. 2020 [cited 2020 8/7/2020]; Available from: admissions.tufts.edu/tuition-and-aid/tuition-and-aid/.

29. Zoom, Zoom Meeting Plans for Your Business. 2020.

30. Neumann, P.J., J.T. Cohen, and M.C. Weinstein, Updating Cost-Effectiveness — The Curious Resilience of the \$50,000-per-QALY Threshold. New England Journal of Medicine, 2014. 371(9): p. 796-797.

31. Paltiel, A.D., A. Zheng, and R.P. Walensky, COVID-19 screening strategies that permit the safe re-opening of college campuses. medRxiv, 2020: p. 2020.07.06.20147702.

32. J. Massey Cashore, N.D., Alyf Janmohamed, Jiayue Wan, Yujia Zhang, Shane Henderson, David Shmoys, Peter Frazier, COVID-19 Mathematical Modeling for Cornell's Fall Semester. 2020, Cornell University. 
Table 1. Input parameters for an analysis of COVID-19 mitigation strategies on US college campuses among students, faculty, and community members.

\begin{tabular}{|c|c|c|c|}
\hline Parameter & & Value & \\
\hline \multicolumn{4}{|l|}{ Cohort characteristics } \\
\hline \multirow[t]{2}{*}{ Cohort size } & & 105,000 & \\
\hline & Students & Faculty & Community \\
\hline Cohort distribution across transmission groups & 0.0476 & 0.0095 & 0.9429 \\
\hline \multicolumn{4}{|l|}{ Age distribution, $\%$} \\
\hline$<20$ & 1 & 0 & 0 \\
\hline $20-59 y$ & 0 & 0.75 & 0.84 \\
\hline$>60 y$ & 0 & 0.25 & 0.16 \\
\hline \multicolumn{4}{|l|}{ Initial disease distribution } \\
\hline Susceptible & 0.89 & 0.94 & 0.81 \\
\hline Infected incubation & 0.005 & 0.005 & 0.01 \\
\hline Infected asymptomatic & 0.005 & 0.005 & 0.01 \\
\hline Infected mild/moderate symptoms & 0 & 0 & 0.01 \\
\hline Infected severe/critical symptoms & 0 & 0 & 0.01 \\
\hline Recovered & 0.10 & 0.05 & 0.15 \\
\hline
\end{tabular}


Table 1, continued. Input parameters for an analysis of COVID-19 mitigation strategies on US college campuses among students, faculty, and community members.

\begin{tabular}{|c|c|c|c|}
\hline Parameter & & Value & \\
\hline \multicolumn{4}{|l|}{ Interventions } \\
\hline Infectivity contact/hour & & 0.002 & \\
\hline \multicolumn{4}{|c|}{ Transmission rate/day students-students (undiagnosed) } \\
\hline Campus closed & & 0.142 & \\
\hline No intervention & & 0.238 & \\
\hline Minimal social distancing & & 0.167 & \\
\hline Extensive social distancing & & 0.141 & \\
\hline Masks & & 0.128 & \\
\hline Extensive social distancing + Masks & & 0.105 & \\
\hline Contact hours $^{\mathrm{a}}$ & Students & Faculty & Community \\
\hline \multicolumn{4}{|l|}{ No intervention } \\
\hline Students & 149.41 & 1.51 & 3.86 \\
\hline Faculty & 37.10 & 10.00 & 33.50 \\
\hline Community & 0.50 & 0.30 & 81.36 \\
\hline
\end{tabular}


Table 1, continued. Input parameters for an analysis of COVID-19 mitigation strategies on US college campuses among students, faculty, and community members.

\begin{tabular}{|c|c|c|c|}
\hline Parameter & & Value & \\
\hline \multicolumn{4}{|c|}{ Interventions, continued } \\
\hline Contact hours $^{\mathrm{a}}$ & Students & Faculty & Community \\
\hline \multicolumn{4}{|c|}{ Minimal social distancing } \\
\hline Students & 109.94 & 1.51 & 3.86 \\
\hline Faculty & 37.10 & 10.00 & 33.50 \\
\hline Community & 0.50 & 0.30 & 81.36 \\
\hline \multicolumn{4}{|c|}{ Extensive social distancing } \\
\hline Students & 90.69 & 0.76 & 3.86 \\
\hline Faculty & 14.84 & 8.00 & 32.79 \\
\hline Community & 0.40 & 0.30 & 71.08 \\
\hline \multicolumn{4}{|l|}{ Residence isolation } \\
\hline Students & 31.8 & 0 & 0 \\
\hline Faculty & 0 & 0 & 3 \\
\hline Community & 0 & 0 & 3 \\
\hline
\end{tabular}


Table 1, continued. Input parameters for an analysis of COVID-19 mitigation strategies on US college campuses among students, faculty, and community members.

\begin{tabular}{|c|c|c|c|}
\hline Parameter & & Value & \\
\hline \multicolumn{4}{|c|}{ Interventions, continued } \\
\hline Contact hours $^{\mathrm{a}}$ & Students & Faculty & Community \\
\hline \multicolumn{4}{|l|}{ Designated isolation } \\
\hline Students & 3 & 0 & 0.5 \\
\hline Faculty & 0 & 0 & 3 \\
\hline Community & 0 & 0 & 3 \\
\hline \multicolumn{4}{|l|}{ Hospitalization } \\
\hline Students & 0 & 0 & 0.5 \\
\hline Faculty & 0 & 0 & 0.5 \\
\hline Community & 0.5 & 0.5 & 0.5 \\
\hline
\end{tabular}


Table 1, continued. Input parameters for an analysis of COVID-19 mitigation strategies on US college campuses among students, faculty, and community members.

\begin{tabular}{|c|c|c|c|}
\hline Parameter & & Value & \\
\hline \multicolumn{4}{|l|}{ Adherence to NPIs } \\
\hline & Students & Faculty & Community \\
\hline Masks & 0.5 & 1 & 0.5 \\
\hline Truthfulness in symptoms reporting & 0.5 & 0.9 & $\mathrm{n} / \mathrm{a}$ \\
\hline Adherence to Residence Isolation & 0.6 & 1 & $\mathrm{n} / \mathrm{a}$ \\
\hline \multicolumn{4}{|l|}{ Test characteristics } \\
\hline \multicolumn{4}{|l|}{ Sensitivity (day of infection) } \\
\hline $1-4$ & & 0.165 & \\
\hline $5-9$ & & 0.710 & \\
\hline $10-21$ & & 0.435 & \\
\hline$>22$ & & 0.000 & \\
\hline Specificity, \% & & 100 & \\
\hline
\end{tabular}


Table 1, continued. Input parameters for an analysis of COVID-19 mitigation strategies on US college campuses among students, faculty, and community members.

\begin{tabular}{lc}
\hline Parameter & Value \\
\hline Costs (USD) & \\
\hline Interventions $^{\mathrm{b}}$ & 151,500 \\
$\qquad \begin{array}{l}\text { Minimal social distancing } \\
\text { Extensive social distancing }\end{array}$ & 407,500 \\
$\qquad$ Masks & 370,000 \\
$\qquad$ Extensive social distancing + Masks & 620,000 \\
Laboratory SARs-Cov-2 diagnostic test (per test) & 10 \\
Student quarantine room (per day) & 30 \\
Hospital inpatient cost (per day) & 1,640 \\
ICU cost (per day) & 2,680 \\
\hline
\end{tabular}

${ }^{\mathrm{a}}$ For example, a student attending an 1-hour discussion session with 10 students will accrue 15 contact-hours.

${ }^{\mathrm{b}}$ Intervention costs were totaled based on which NPIs and mobility restrictions were included and included masks, cleaning, and software costs.

Abbreviations: NPIs: Non-pharmacologic interventions. ICU: intensive care unit. 
Table 2. Clinical outcomes among students and faculty by strategy (results are reported per 5,000 students and 1,000 faculty)

\begin{tabular}{|c|c|c|c|c|c|c|c|c|}
\hline \multirow{3}{*}{ NPIs } & \multicolumn{5}{|l|}{ Isolation } & \multirow{3}{*}{$\begin{array}{l}\text { Total } \\
\text { tests }\end{array}$} & \multirow{3}{*}{$\begin{array}{l}\text { Total student } \\
\text { isolation days }\end{array}$} & \multirow{3}{*}{$\begin{array}{l}\text { Asymptomatic } \\
\text { in isolation, \% }\end{array}$} \\
\hline & location & Testing & \multicolumn{3}{|c|}{ Infections } & & & \\
\hline & & & Students & Faculty & Total & & & \\
\hline Campus closed & $\mathrm{n} / \mathrm{a}$ & $\mathrm{n} / \mathrm{a}$ & 1,401 & 26 & 1,427 & -- & -- & -- \\
\hline No intervention & $\mathrm{n} / \mathrm{a}$ & $\mathrm{n} / \mathrm{a}$ & 3,746 & 164 & 3,910 & -- & -- & -- \\
\hline \multicolumn{9}{|c|}{ Minimal social distancing } \\
\hline & ResIsol & Self-screen & 3,147 & 131 & 3,278 & -- & 2,510 & -- \\
\hline & DesigIsol $^{\mathrm{a}}$ & Self-screen & 3,290 & 140 & 3,430 & 1,057 & 2,325 & -- \\
\hline & DesigIsol & 1-time LT & 3,146 & 125 & 3,271 & 6,973 & 2,183 & 0.08 \\
\hline & DesigIsol & RLTq14 & 2,441 & 102 & 2,543 & 42,560 & 3,850 & 0.45 \\
\hline & DesigIsol & RLTq7 & 1,479 & 71 & 1,550 & 80,569 & 3,162 & 0.57 \\
\hline & DesigIsol & RLTq3 & 713 & 54 & 767 & 140,977 & 2,170 & 0.58 \\
\hline
\end{tabular}


Table 2, continued. Clinical outcomes among students and faculty by strategy (results are reported per 5,000 students and 1,000 faculty)

\begin{tabular}{|c|c|c|c|c|c|c|c|c|}
\hline \multirow{3}{*}{ NPIs } & \multicolumn{5}{|l|}{ Isolation } & \multirow{3}{*}{$\begin{array}{l}\text { Total } \\
\text { tests }\end{array}$} & \multirow{3}{*}{$\begin{array}{l}\text { Total student } \\
\text { isolation days }\end{array}$} & \multirow{3}{*}{$\begin{array}{l}\text { Asymptomatic } \\
\text { in isolation, \% }\end{array}$} \\
\hline & location & Testing & \multicolumn{3}{|c|}{ Infections } & & & \\
\hline & & & Students & Faculty & Total & & & \\
\hline \multicolumn{9}{|c|}{ Extensive Social Distancing } \\
\hline & ResIsol & Self-screen & 1,927 & 52 & 1,979 & -- & 1,416 & -- \\
\hline & DesigIsol $^{\mathrm{a}}$ & Self-screen & 2,188 & 73 & 2,260 & 655 & 1,337 & -- \\
\hline & DesigIsol & 1-time LT & 1,998 & 64 & 2,062 & 6,576 & 1,334 & 0.04 \\
\hline & DesigIsol & RLTq14 & 1,167 & 45 & 1,213 & 44,259 & 1,788 & 0.46 \\
\hline & DesigIsol & RLTq7 & 595 & 40 & 635 & 83,233 & 1,393 & 0.54 \\
\hline & DesigIsol & RLTq3 & 274 & 35 & 309 & 144,153 & 897 & 0.59 \\
\hline \multicolumn{9}{|l|}{ Masks } \\
\hline & ResIsol & Self-screen & 1,519 & 51 & 1,570 & -- & 1,133 & -- \\
\hline & DesigIsol $^{\mathrm{a}}$ & Self-screen & 1,456 & 48 & 1,504 & 454 & 841 & -- \\
\hline & DesigIsol & 1-time PCR & 1,437 & 50 & 1,487 & 6,429 & 968 & 0.04 \\
\hline
\end{tabular}


Table 2, continued. Clinical outcomes among students and faculty by strategy (results are reported per 5,000 students and 1,000 faculty).

\begin{tabular}{|c|c|c|c|c|c|c|c|c|}
\hline \multirow{3}{*}{ NPIs } & \multicolumn{5}{|l|}{ Isolation } & \multirow{3}{*}{$\begin{array}{l}\text { Total } \\
\text { tests }\end{array}$} & \multirow{3}{*}{$\begin{array}{l}\text { Total student } \\
\text { isolation days }\end{array}$} & \multirow{3}{*}{$\begin{array}{l}\text { Asymptomatic } \\
\text { in isolation, \% }\end{array}$} \\
\hline & location & Testing & \multicolumn{3}{|c|}{ Infections } & & & \\
\hline & & & Students & Faculty & Total & & & \\
\hline \multicolumn{9}{|c|}{ Masks, continued } \\
\hline & DesigIsol $^{\mathrm{a}}$ & RLTq14 & 689 & 35 & 724 & 44,802 & 1,068 & 0.46 \\
\hline & DesigIsol & RLTq7 & 437 & 32 & 468 & 83,687 & 1,043 & 0.54 \\
\hline & DesigIsol & RLTq3 & 215 & 26 & 241 & 144,455 & 763 & 0.62 \\
\hline \multicolumn{9}{|c|}{ Extensive Social Distancing + Masks } \\
\hline & ResIsol & Self-screen & 493 & 28 & 521 & -- & 391 & -- \\
\hline & DesigIsol $^{\mathrm{a}}$ & Self-screen & 508 & 29 & 537 & 220 & 339 & -- \\
\hline & DesigIsol & 1-time LT & 606 & 28 & 634 & 6,219 & 495 & 0.08 \\
\hline & DesigIsol & RLTq14 & 268 & 27 & 295 & 45,313 & 539 & 0.46 \\
\hline & DesigIsol & RLTq7 & 182 & 29 & 211 & 84,501 & 495 & 0.57 \\
\hline & DesigIsol & RLTq3 & 151 & 25 & 176 & 145,219 & 574 & 0.58 \\
\hline
\end{tabular}

aAdmission to quarantine if 'positive' symptom screen is confirmed by laboratory testing. 
Abbreviations: ResIsol: residence isolation in student dorm room; DesigIsol: student quarantine in separate location. LT: laboratory test; RLT: routine laboratory test every X days. 
Table 3. Cost-effectiveness of COVID-19 mitigation strategies on US college campuses.

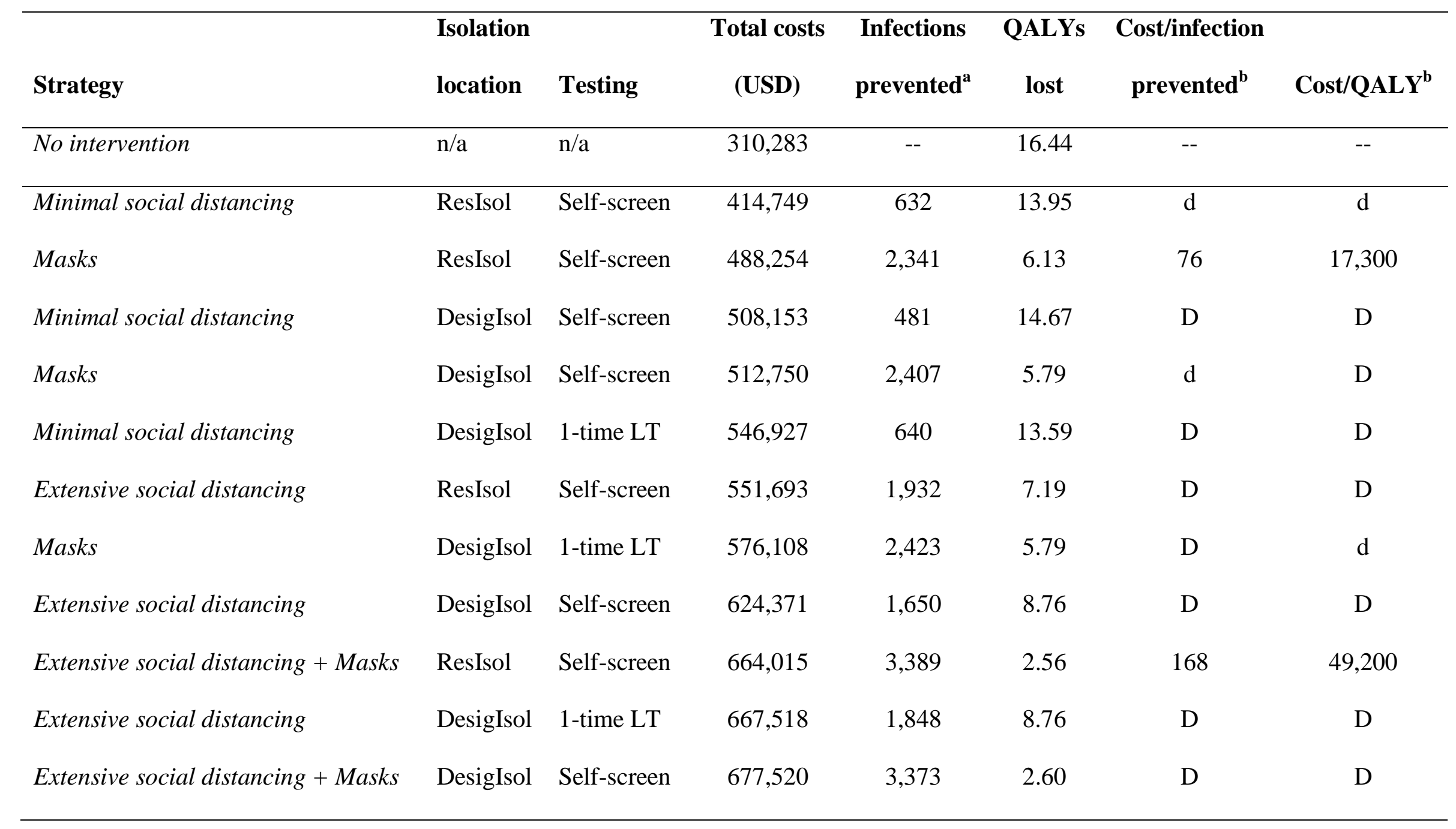


Table 3, continued. Cost-effectiveness of COVID-19 mitigation strategies on US college campuses.

\begin{tabular}{|c|c|c|c|c|c|c|c|}
\hline & Isolation & & Total costs & Infections & QALYs & Cost/infection & \\
\hline Strategy & location & Testing & (USD) & prevented $^{\mathrm{a}}$ & lost & prevented $^{\mathrm{b}}$ & $\operatorname{Cost} / \mathbf{Q A L Y} \mathbf{Y}^{\mathrm{b}}$ \\
\hline Extensive social distancing + Masks & DesigIsol & 1-time LT & 747,829 & 3,276 & 2.81 & $\mathrm{D}$ & $\mathrm{D}$ \\
\hline Minimal social distancing & DesigIsol & RLTq14 & 898,542 & 1,367 & 11.23 & $\mathrm{D}$ & $\mathrm{D}$ \\
\hline Masks & DesigIsol & RLTq14 & 909,557 & 3,186 & 3.47 & $\mathrm{D}$ & $\mathrm{D}$ \\
\hline Extensive social distancing & DesigIsol & RLTq14 & 997,635 & 2,698 & 5.19 & $\mathrm{D}$ & $\mathrm{D}$ \\
\hline Campus closed $^{c}$ & $\mathrm{n} / \mathrm{a}$ & $\mathrm{n} / \mathrm{a}$ & $1,099,181$ & 2,483 & 4.46 & $\mathrm{D}$ & $\mathrm{D}$ \\
\hline Extensive social distancing + Masks & DesigIsol & RLTq14 & $1,118,667$ & 3,615 & 2.00 & 2,008 & 811,400 \\
\hline Minimal Social Distancing & DesigIsol & RLTq7 & $1,183,393$ & 2,360 & 7.38 & $\mathrm{D}$ & $\mathrm{D}$ \\
\hline Masks & DesigIsol & RLTq7 & $1,280,258$ & 3,442 & 2.71 & $\mathrm{D}$ & $\mathrm{D}$ \\
\hline Extensive social distancing & DesigIsol & RLTq7 & $1,337,494$ & 3,275 & 3.54 & $\mathrm{D}$ & $\mathrm{D}$ \\
\hline Extensive social distancing + Masks & DesigIsol & RLTq7 & $1,504,746$ & 3,699 & 1.88 & 4,596 & $\mathrm{~d}$ \\
\hline Minimal social distancing & DesigIsol & RLTq3 & $1,702,406$ & 3,143 & 4.65 & $\mathrm{D}$ & $\mathrm{D}$ \\
\hline Masks & DesigIsol & RLTq3 & $1,863,026$ & 3,669 & 1.88 & $\mathrm{D}$ & $\mathrm{D}$ \\
\hline Extensive social distancing & DesigIsol & RLTq3 & $1,909,521$ & 3,601 & 2.47 & $\mathrm{D}$ & $\mathrm{D}$ \\
\hline Extensive social distancing + Masks & DesigIsol & RLTq3 & $2,110,595$ & 3,735 & 1.64 & 17,200 & $2,804,600$ \\
\hline
\end{tabular}


${ }^{\mathrm{a}}$ Compared to No intervention.

${ }^{\mathrm{b}} \mathrm{A}$ strategy is dominated if it is more costly and less effective than another strategy (strong dominance, "D") or some combination of other strategies (weak dominance, “d”). ICERs are rounded to \$100.

${ }^{\mathrm{c}}$ Assuming that 100 students defer enrollment for the semester because the campus is closed.

Abbreviations: USD: US dollars; QALY: quality-adjusted life-year; ResIsol: residence isolation in student dorm room; DesigIsol: student quarantine in separate location; LT: laboratory test; RLT: routine laboratory test every X days. 
Figure 1. Infections and costs by COVID-19 mitigation strategy

\section{A. Student infections}

4,000

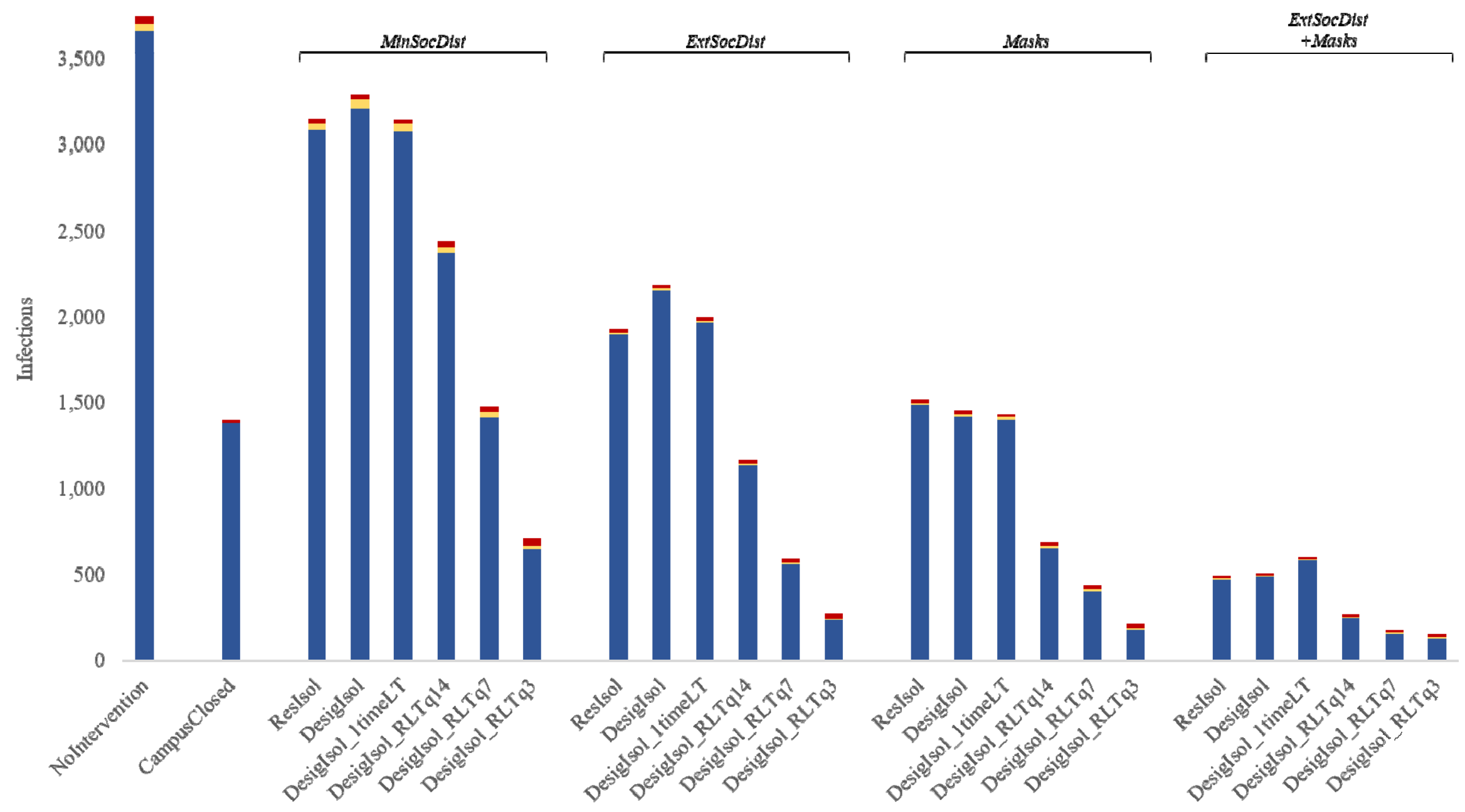




\section{B. Faculty infections}

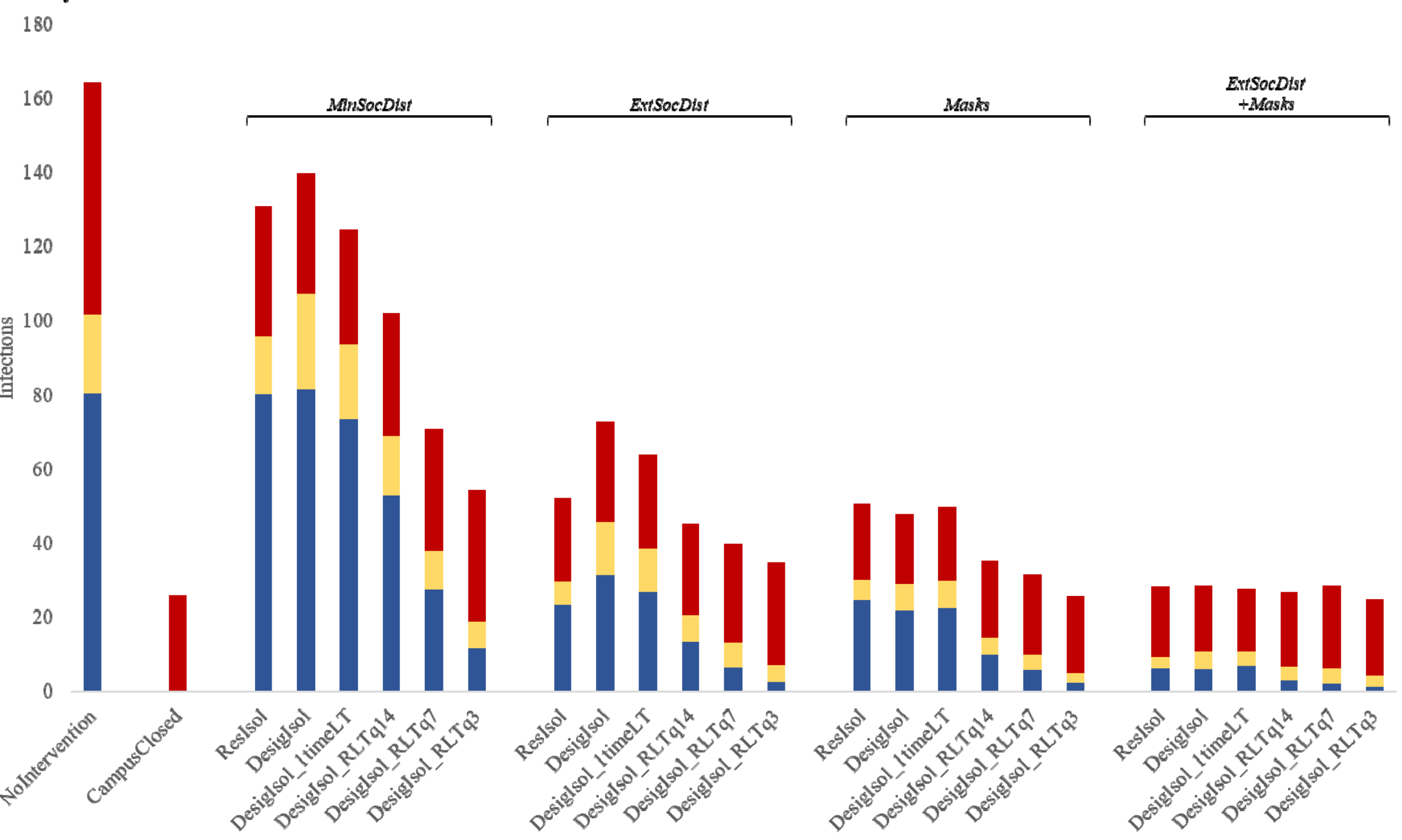


$\$ 2,500,000$
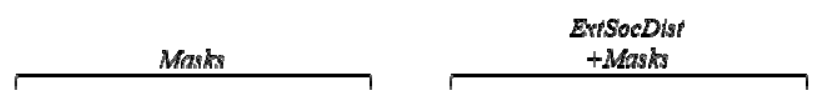

$\$ 2,000,000$

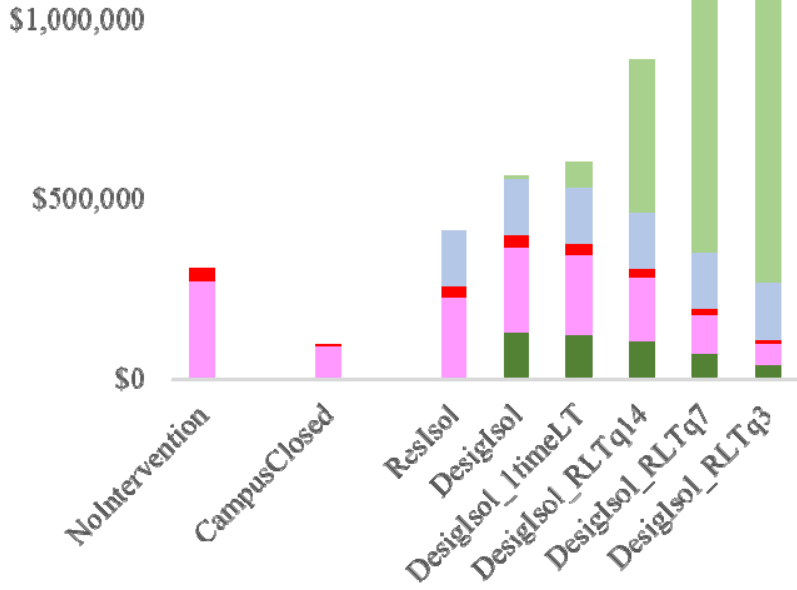

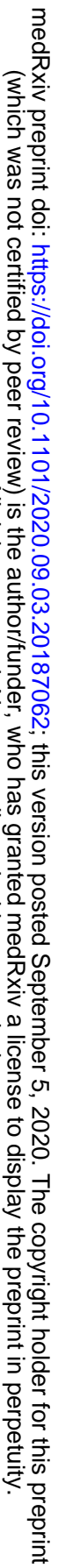


Figure 2. Efficiency Frontier (\$/infection-prevented)

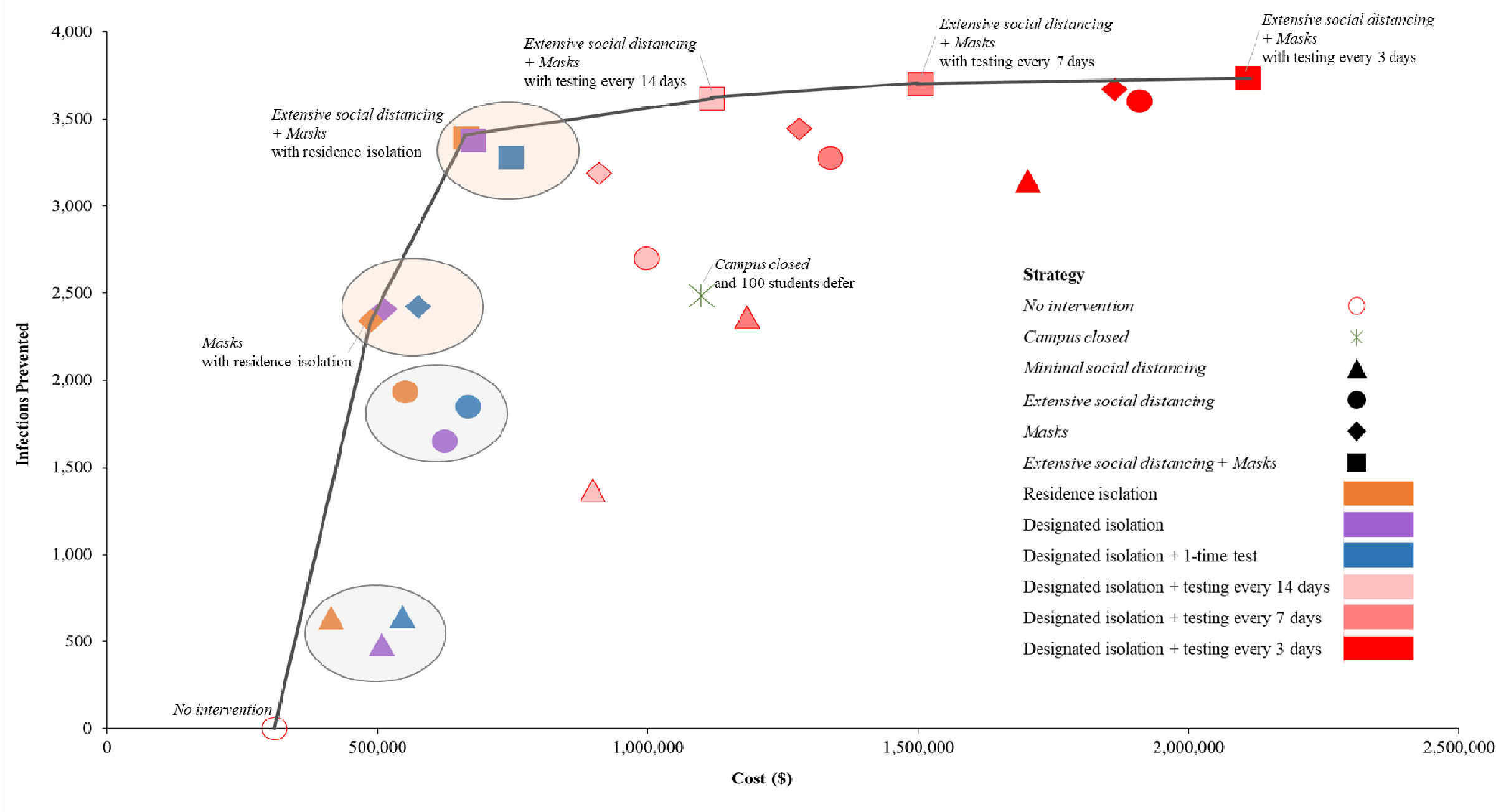

